\title{
Políticas públicas ambientales y desarrollo turístico sostenible en las áreas protegidas de Ecuador
}

\author{
Environmental public policies and sustainable tourism development in \\ Ecuador's protected areas
}

Iván Mendoza-Montesdeoca

imendozam@espam.edu.ec@0000-0001-7632-144X

Escuela Superior Politécnica Agropecuaria de Manabí (ESPAM MFL).

Matriz de Calceta. Avda. 10 de agosto, $n^{\circ} 82$ y Granda Centeno. Ecuador

Manuel Rivera-Mateos

manuel.rivera@uco.es @ 0000-0003-2780-380X

Universidad de Córdoba. Plaza del Cardenal Salazar, 1. 14071 Córdoba, España

Yamil Doumet-Chilán

ndoumet@espam.edu.ec @ 0000-0003-4295-5270

Escuela Superior Politécnica Agropecuaria de Manabí (ESPAM MFL).

Matriz de Calceta. Avda. 10 de agosto, $n^{\circ} 82$ y Granda Centeno, Ecuador

\section{INFO ARTÍCULO}

Recibido: 02/09/2021

Revisado: 01/01/2022

Aceptado: 12/01/2022

\section{PALABRAS CLAVE}

Turismo

Políticas ambientales

Áreas protegidas

Espacios naturales

Desarrollo turístico sostenible

Ecuador

\section{KEYWORDS}

Tourism

Environmental policies

Protected Areas

Natural spaces

Sustainable tourism development

Ecuador

\begin{abstract}
RESUMEN
Análisis crítico de las políticas públicas de conservación, gestión ambiental y desarrollo turístico en los espacios naturales protegidos de Ecuador para detectar sus disfunciones, contradicciones y problemas de aplicabilidad. Se utiliza una metodología de investigación predominantemente exploratoria y con enfoque descriptivo-analítico a la hora de estudiar y sistematizar las distintas normativas, acciones y directrices existentes e implementadas por parte de organismos internacionales y nacionales con competencias en conservación ambiental y desarrollo sostenible, las cuales se sistematizan y analizan a través de los principales documentos de interés que recogen principios, lineamientos estratégicos y normas específicas de aplicación. Se han identificado a través de fuentes primarias y secundarias y documentación interna de diversas Administraciones los efectos e impactos más visibles que han generado estas políticas en la protección y/o valorización del patrimonio natural, así como en el desarrollo turístico compatible con la conservación de estos espacios, la generación de ingresos complementarios y la diversificación económica para las comunidades locales. Se concluye que la normativa ecuatoriana sobre conservación de áreas protegidas presenta notables puntos de colisión y falta de coherencia o coordinación con las políticas sectoriales de turismo. Esto es consecuencia de la falta de una visión estratégica y de planificación territorial como destinos turísticos sostenibles y la inexistencia de un marco de gestión, ordenación y planificación compartida y colaborativa entre los distintos agentes locales.
\end{abstract}

\begin{abstract}
Critical analysis of public policies on environmental conservation, management, and tourism development in the protected natural areas of Ecuador to detect their dysfunctions, contradictions, and problems of applicability. A predominantly exploratory research methodology with a descriptive-analytical approach is used when studying and systematizing the different regulations, actions and guidelines existing and implemented by international and national organizations with competencies in environmental conservation and sustainable development. These are systematized and analyzed through the main documents of interest that include principles, strategic guidelines, and specific rules of application.
\end{abstract}




\begin{abstract}
Through primary and secondary sources, and internal documentation of various Administrations we have identified the most visible effects and impacts that these policies have generated in the protection and/or valorization of the natural heritage, as well as in the tourist development compatible with the conservation of these spaces, the generation of complementary income and economic diversification for local communities. We concluded that Ecuadorian regulations on the conservation of protected areas present notable points of collision and lack of coherence or coordination with tourism policies. This is the consequence of two main factors: the lack of a broad strategic vision and comprehensive territorial planning of these territories as sustainable tourist destinations and the lack of a framework for management, planning and collaborative planning between the different local agencies and agents that affect these spaces.
\end{abstract}

\title{
1. INTRODUCCIÓN
}

La Unión Internacional para la Conservación de la Naturaleza (UICN, 2011) sostiene que en los espacios naturales protegidos la ausencia de políticas públicas o normativas específicas no es muchas veces el problema principal, sino más bien la falta de integración y coherencia de las estrategias y planes sobre biodiversidad derivados de las distintas acciones sectoriales que inciden en un mismo espacio protegido y, en definitiva, la falta de un sistema de gobernanza que determine de manera racional y eficiente las normas, el reparto competencial, las funciones institucionales y los procesos e instrumentos de gestión y evaluación. En esta misma línea, Coreau, Guillet y Rabaud (2018) señalan que los investigadores y profesionales vinculados a la ecología y el desarrollo sostenible han de trabajar conjuntamente en la definición de nuevas estrategias de gobernanza y políticas públicas para las áreas protegidas y la preservación de sus servicios ecosistémicos y biodiversidad. Según Forleo y Palmeri (2018), estos constituyen, a su vez, un instrumento de soporte y cualificación, por ejemplo, de numerosas actividades recreativas y de ocio demandadas por numerosas personas. Por lo tanto, es muy necesario analizar -como pretendemos aquí- si la normativa nacional que persigue alcanzar objetivos de conservación y un uso turístico sustentable, así como las políticas públicas sobre las áreas protegidas de Ecuador, realmente responden a las necesidades demandadas por los visitantes, los agentes turísticos y las comunidades locales.

La Organización Mundial del Turismo (OMT, 2016) ha señalado el año 2015 como decisivo para el desarrollo mundial al haber aprobado los Gobiernos la Agenda 2030 para el Desarrollo Sostenible, junto con los Objetivos de Desarrollo Sostenible (ODS), un conjunto de 17 Objetivos con 169 metas asociadas que se centran en las personas de manera transformadora y universal. Y precisamente en este ámbito el turismo se ha considerado como un instrumento útil que puede contribuir, directa o indirectamente, a la consecución de dichos ODS y particularmente respecto a su vinculación más directa con los objetivos 8,12 y 14 relacionados con el crecimiento económico sostenible, así como con los procesos de consumo y de producción sostenibles. De acuerdo con lo que establece la Agenda 2030, el turismo sostenible está llamado a ser uno de los principales medios para prevenir y evitar los impactos negativos derivados de las presiones antrópicas e intereses comerciales cortoplacistas comerciales y el uso masivo e irracional de los recursos patrimoniales desde un enfoque desarrollista, economicista y no sustentable a largo plazo.

La Unión Internacional para la Conservación de la Naturaleza (UICN, 2014) también ha reconocido que en las últimas décadas no solo se ha dado un aumento significativo en el número de áreas protegidas a nivel mundial, sino que también se ha producido un significativo cambio en la comprensión acerca de cómo pueden y deben ser gobernados y gestionados estos espacios. De esta manera, la creación de áreas protegidas se ha convertido en una herramienta indispensable para la conservación, haciendo que las políticas públicas implementen la creación de normativas cuyo objetivo principal sea buscar una coexistencia sostenible entre el medio ambiente, la población local y las expectativas de desarrollo socioeconómico.

Pero como señalan Rodríguez y Ávila (2014), las políticas de protección ambiental presentan una gran complejidad en su aplicación por cuanto se entrelazan en ellas diferentes políticas sectoriales, variables y enfoques territoriales que en la práctica requieren de políticas más integrales que superen el mero enfoque sectorial. Si a ello unimos la existencia en muchos países de un inadecuado marco institucional y 
competencial, la falta de unas estrategias de gobernanza específicas para estos espacios protegidos, la escasa participación y sensibilización del tejido social y ciudadano o la escasa estructuración y vertebración del mapa de actores implicados, el compendio de normas legales se hace obviamente inaplicable desde el punto de vista operativo. Por esto, autores como Meinard (2017) y Ward, Stringer y Holmes (2018), insisten en la necesidad de articular políticas públicas integrales e intersectoriales en estas áreas protegidas con voluntad política de coordinación y cooperación interinstitucional y público-privada y con financiación suficiente en el ámbito de estas áreas protegidas y sus áreas de influencia. Además, estas políticas deben someterse a un proceso de medición y evaluación de resultados y de impactos (Gibson et al., 2017), más aún cuando las políticas ambientales pretenden paralelamente promover otros fines que van más allá de la conservación ambiental como las actividades económicas sostenibles y el desarrollo local.

Los nuevos modelos de gestión de las áreas protegidas deben considerar a éstas como territorios que mantienen en mayor o menor grado semejanzas entre sí: biológicas, geográficas, paisajísticas, de ciertos niveles de éxito (y a veces hasta de fracaso) de sus actividades de gestión y manejo de sus ecosistemas y recursos, parecidos niveles de incidencia de las actividades humanas, etc. (Yánez et al., 2013). Por tanto, es necesario conocer de qué forma se están ejecutando acciones y estrategias planificadas en los modelos de desarrollo planteados en estos espacios, de manera que se puedan establecer análisis comparativos y extraer lecciones aprendidas y casos de referencia de buenas prácticas extrapolables, en mayor o menor medida, a otros territorios. Asimismo, también resulta imprescindible precisar si dichos modelos se enmarcan realmente en los principios y objetivos de una política de sostenibilidad, sobre todo con la obligación de brindar garantías de conservación del patrimonio natural y al mismo tiempo permitir mayores oportunidades de participación a las comunidades locales, cuya economía y supervivencia dependen, en definitiva, de los recursos y sistemas ecosistémicos de las áreas protegidas como las que aquí referimos de Ecuador.

No es casualidad que al menos a nivel de discurso teórico y político en los últimos años, las organizaciones públicas y privadas de todo tipo hayan comenzado a reconocer las conexiones e interdependencias entre las dimensiones económicas, ambientales y sociales de la sostenibilidad y, de hecho, es comúnmente aceptado que las políticas nacionales para el desarrollo de las áreas protegidas han de definir y comprender el conjunto de principios, objetivos, marco legal e institucional, líneas estratégicas, instrumentos de gestión y resultados esperados para garantizar la provisión de bienes y servicios ambientales y la conservación de la diversidad biológica para el bienestar social y económico de sus poblaciones (CONAP, 1999 y Forleo, 2018).

Como señala Paz (2018) existen aproximadamente 202.000 áreas protegidas en el mundo, las cuales cubren el $17,7 \%$ del área total terrestre del planeta, suponiendo que "la puntuación promedio de la huella humana dentro de estos espacios es de 3,3, esto es, casi un $50 \%$ más bajo que la media global que se cifra en 6,16 puntos. No obstante, a pesar de estos datos relativamente favorables, las actividades humanas son frecuentes en muchas áreas protegidas y solo el $42 \%$ de estos territorios están libres de cualquier presión antrópica". Las áreas protegidas con objetivos estrictos de conservación de la biodiversidad (categorías 1 y 2 de la Unión Internacional para la Conservación de la Naturaleza, UICN) tienen menor presión humana que las categorías 3 a 6 . Esto en parte se debe a que estas últimas categorías permiten algunas actividades y la explotación sostenible de los recursos territoriales.

Las amenazas directas e indirectas que afectan a la conservación de estos espacios que prestan importantes servicios ecosistémicos y cuentan con un patrimonio natural que sirve de soporte básico para el turismo sostenible, pueden encontrar su punto de inflexión si se adopta una eficiente toma de decisiones en materia de planificación y gestión del territorio y un sistema de gobernanza colaborativa con los agentes del sector privado, el tejido productivo y la propia comunidad local, promoviendo un compromiso entre las partes en materia de sostenibilidad. Pero resulta evidente, en cualquier caso, que el concepto tradicional de "área protegida" ha sido ampliamente superado, y en las últimas décadas, los espacios protegidos están asumiendo fines muy diversos y alejados de sus objetivos primigenios (conservación de la naturaleza, investigación científica, educación ambiental, turismo y recreación...), y de ahí la tendencia a declarar piezas cada vez más extensas que abarcan comarcas enteras con un predominio absoluto de tierras de propiedad privada y una clara situación de marginalidad y declive demográfico y socioeconómico. Además, a éstas se les exige, entre otras cosas, que doten de un distintivo de calidad a las actividades o productos que se 
generen en su seno, que contribuyan a la salvaguarda de los bienes del patrimonio cultural radicados en su interior, o que sean referentes de iniciativas de desarrollo socioeconómico endógenos en diferentes ámbitos, sobre todo turísticos, entre otros muchos cometidos (Mulero \& Rivera, 2019). Por ello mismo, la adopción de nuevos sistemas de gobernanza y planificación integral y no meramente sectorial se hace aún más necesaria.

Sólo desde la confluencia de los vectores antedichos pueden explicarse precisamente las cifras tan amplias de territorios a nivel mundial que se encuentran sujetos a protección bajo alguna figura de corte internacional, estatal o autonómica y todo parece apuntar, además, a que los nuevos espacios protegidos se han concebido, en buena medida, como una herramienta para un nuevo modelo de desarrollo integral más allá de la mera conservación del medio natural. De esta manera, hoy se espera que las masivas declaraciones recientes de espacios protegidos contribuyan a la dinamización socioeconómica de extensas áreas rurales a través de inversiones públicas, planes de desarrollo sostenible $u$ otras estrategias. $Y$, en este sentido, Herrera (2020), en un estudio realizado sobre la política turística en Ecuador en el periodo 2009-2013, determinó que las acciones ejecutadas evidenciaron una lógica de actuación muy sesgada y orientada meramente a la consecución de objetivos rectores de política económica cortoplacista en los que la política pública turística a nivel nacional no obtuvo, desde luego, resultados tangibles exitosos y sustantivos, a lo que se sumó el divorcio o escasas sinergias positivas entre la política de turismo y la gestión ambiental de las áreas protegidas. De hecho, los objetivos y enfoques de ambas políticas públicas son desafortunadamente en muchos casos muy diferentes y se aplican por administraciones distintas a modo de compartimentos estancos, sobre todo en sus etapas iniciales (Ngo et al., 2018), pese a que los gestores de destinos suelen reconocer a nivel de discurso teórico que la mejor vía de desarrollo turístico es la planificación integral y no meramente sectorial de los recursos territoriales de los espacios protegidos (Lundberg, 2015).

Pero pese a estas evidencias, consideraciones y realidades sobre la gobernanza de los espacios naturales protegidos, lo cierto es que aún son relativamente escasos los estudios de caso que analicen con detalle y de manera demostrativa las consecuencias y resultados de las políticas públicas en la dinamización socioeconómica en general y turístico-recreativa en particular de las áreas protegidas y las comunidades locales de sus áreas de influencia. Esto si cabe es aún más evidente en países como Ecuador, donde estas políticas son relativamente recientes y apenas han trascendido del discurso teórico recurrente con pocas acciones sustantivas, contrastadas y evaluadas que puedan servir de ejemplos de buenas prácticas, a lo que se suma la inexistencia de sistemas de información territorial bien desarrollados y capaces de servir de soporte a la todavía débil planificación y gobernanza de estos espacios protegidos.

Debido a esto resultan fundamentales los análisis actualizados y las evaluaciones continuas de la aplicabilidad y efectividad de las políticas públicas propuestas y la ejecución práctica de las estrategias y metas planteadas, por lo que en este trabajo se ha pretendido abordar estas cuestiones con el propósito de realizar un análisis crítico sobre las políticas públicas ambientales puestas en marcha en las áreas protegidas de Ecuador desde la perspectiva de su funcionalidad y orientación para propiciar el desarrollo turístico sostenible, todo esto de manera compatible con la conservación de sus servicios ecosistémicos básicos y su propia biodiversidad.

\section{METODOLOGÍA}

El presente trabajo hace uso de un método de investigación con un enfoque descriptivo y analítico-sintético a través del cual se han sistematizado y analizado las distintas normativas, directrices y estrategias implementadas por organismos internacionales y nacionales con competencias en conservación ambiental y desarrollo turístico sostenible. En concreto, se han tenido en cuenta los principales documentos de interés que recogen principios, lineamientos estratégicos y normas específicas de aplicación, delimitando las dos variables acerca del marco legal establecido y las políticas públicas (la ambiental y la turística), en el marco de la sostenibilidad y el desarrollo integral de los espacios naturales protegidos (tabla 1). 
Tabla 1. Fases metodológicas, fuentes documentales e indicadores utilizados.

\begin{tabular}{|c|c|c|}
\hline $\begin{array}{l}\text { Fase 1. Análisis descriptivo-sintético y } \\
\text { sistematización }\end{array}$ & $\begin{array}{l}\text { Fase } 2 \text {. Establecimiento de } \\
\text { indicadores de referencia }\end{array}$ & $\begin{array}{l}\text { Fase 3. Conclusiones sobre resultados } \\
\text { y deficiencias de las políticas públicas } \\
\text { (ambientales, turísticas) }\end{array}$ \\
\hline $\begin{array}{l}\text { Análisis bibliográfico y documental. } \\
\text { Estado de la cuestión }\end{array}$ & $\begin{array}{l}\text { Indicadores de competitividad y } \\
\text { sostenibilidad turística del Foro } \\
\text { Económico Mundial referidos a } \\
\text { Ecuador (2015-2020). }\end{array}$ & $\begin{array}{l}\text { Análisis crítico de las políticas públicas } \\
\text { puestas en marcha y sus disfunciones, } \\
\text { contradicciones y problemas de } \\
\text { aplicabilidad. Valoración en términos } \\
\text { de sostenibilidad turística integral. }\end{array}$ \\
\hline $\begin{array}{l}\text { Marco legal e institucional con } \\
\text { incidencia en el manejo y gestión } \\
\text { de las áreas protegidas desde la } \\
\text { perspectiva ambiental y de desarrollo } \\
\text { turístico sostenible. }\end{array}$ & $\begin{array}{l}\text { Indicadores de monitoreo para el } \\
\text { manejo turístico y ambiental de los } \\
\text { Planes de Gestión Operativa Anual } \\
\text { (PGOA) de las áreas protegidas de } \\
\text { Ecuador. }\end{array}$ & $\begin{array}{l}\text { Conclusiones a partir de estudio de } \\
\text { indicadores de referencia de la Fase } \\
2 \text { y resultados obtenidos de análisis } \\
\text { bibliográfico y documental (Fase } 1 \text { ). }\end{array}$ \\
\hline $\begin{array}{l}\text { Sistematización de normativas, } \\
\text { estrategias y directrices } \\
\text { implementadas por organismos } \\
\text { internacionales y nacionales con } \\
\text { competencias en conservación } \\
\text { ambiental y desarrollo sostenible. }\end{array}$ & $\begin{array}{l}\text { Objetivos de Desarrollo Sostenible } \\
\text { (ODS) }\end{array}$ & \\
\hline $\begin{array}{l}\text { Explotación de datos estadísticos } \\
\text { sobre turismo y medio ambiente } \\
\text { en espacios protegidos de Ecuador. } \\
\text { Caracterización territorial, ambiental y } \\
\text { socioeconómica del SNAP de Ecuador. }\end{array}$ & & \\
\hline
\end{tabular}

Fuente: Elaboración propia.

Además del análisis crítico de las principales normas legales, estrategias y reglamentos relacionados con la conservación y el desarrollo turístico sostenible de los espacios naturales protegidos de Ecuador, y que se indican en el apartado 4 de resultados, hemos considerado aquellas fuentes de referencia en materia de indicadores de seguimiento de políticas públicas, particularmente el sistema de indicadores de competitividad y sostenibilidad turística del Foro Económico Mundial (Schwab et al., 2017) y los de monitoreo de manejo turístico y ambiental del Manual para la Gestión Operativa de las Áreas Protegidas de Ecuador (Columba, 2013). Con esto se ha pretendido obtener en una fase final una serie de conclusiones y reflexiones, mediante un análisis crítico, sobre la eficacia y eficiencia de la gestión y planificación realizadas en estos espacios protegidos y sobre el comportamiento y dinámica turística detectadas en el Sistema Nacional de Áreas Protegidas de Ecuador respecto a las variables macroeconómicas del turismo a nivel nacional.

\section{SIGNIFICACIÓN AMBIENTAL Y SOSTENIBILIDAD TURÍSTICA DE LOS ESPACIOS NATURALES PROTEGIDOS DE ECUADOR}

Ecuador en 2019, antes de la crisis sanitaria, registró un volumen de turistas superior a los 2,4 millones, principalmente concentrados en los espacios naturales protegidos de Islas Galápagos y la Amazonía. Este flujo turístico generó un total de 1.871 millones de dólares USD en ingresos directos por la actividad turística y más de 2.287 millones en ingresos por divisas por turismo, alcanzándose la mejor cifra de aportación de la actividad turística al PIB Nacional (un 2,2\%) tras un crecimiento continuo en la última década sólo truncado por la crisis de la pandemia del Covid-19 en 2020 (Instituto Geográfico Militar, 2020). Por su parte, la participación del sector turístico en el empleo total del país en 2019 alcanzó un 6,1\%, si bien muy por detrás de sectores económicos como el agrario y el comercial y con cierta tendencia al estancamiento desde 2015, coincidiendo con una situación inestable y de evolución de "dientes de sierra" que se ha venido percibiendo 
en el último sexenio en el comportamiento de la demanda, particularmente en los espacios naturales protegidos, donde se concentra buena parte de la actividad turística (figura 1).

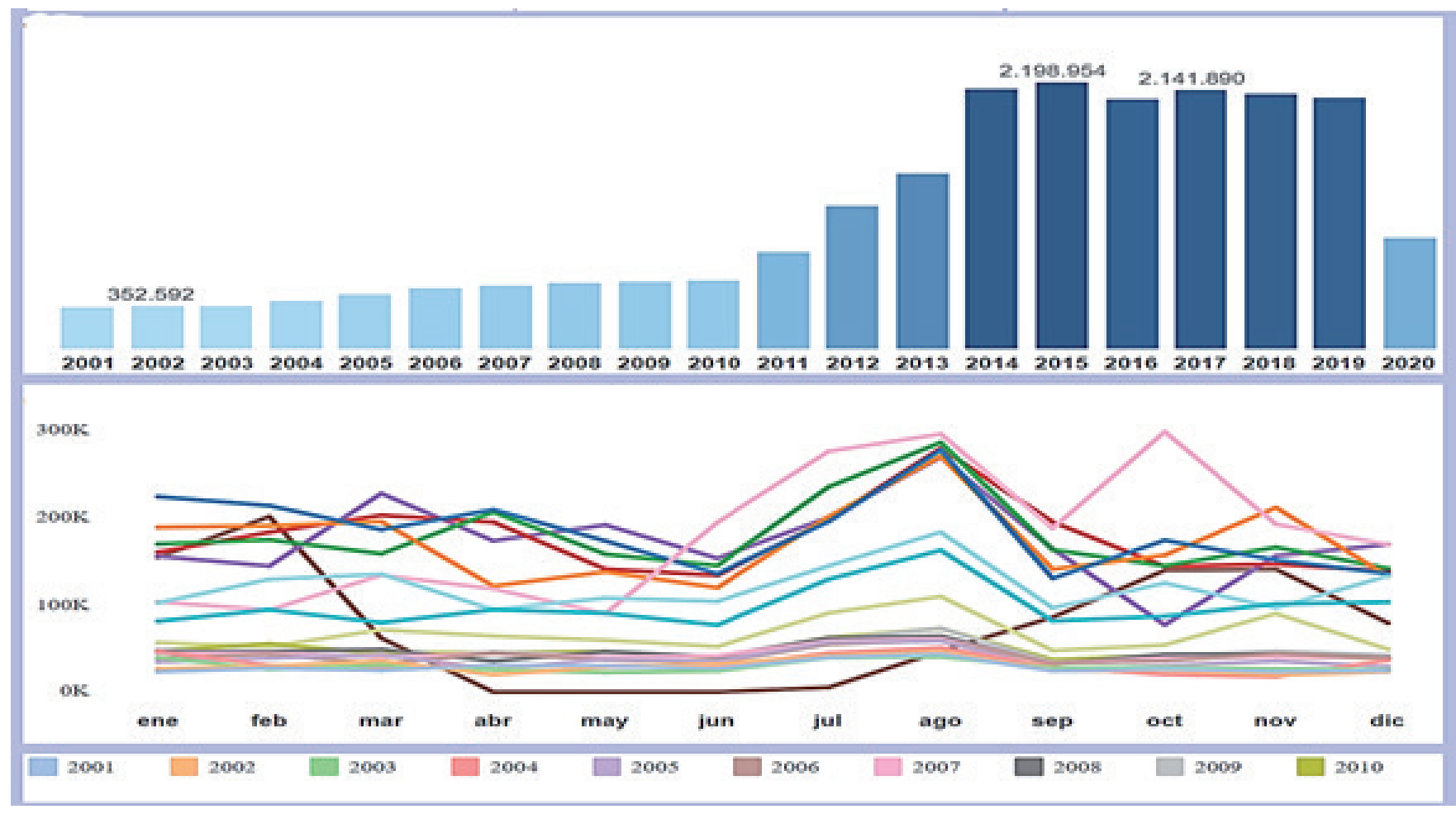

Figura 1. Evolución del número de visitantes en Áreas Protegidas de Ecuador (2001-2020). Fuente: Ministerio del Medio Ambiente (2021). Elaboración propia.

En este sentido, hay que aclarar que en 2019 del total de turistas registrados en Ecuador (2.430.000), unos 2.057.847 (un 84,6\%) visitaron algún espacio natural protegido, siendo el Parque Nacional de MachaliIla, las Islas Galápagos y la Reserva Marino-Costera de Puntilla de Santa Elena los que acapararon una parte muy importante de dichas visitas (figura 2). En consecuencia, la actividad turística en Ecuador se encuentra muy concentrada de manera abrumadora en las áreas naturales de mayor fragilidad ambiental, sobre todo en espacios costero-marítimos e insulares, por lo que los problemas de sostenibilidad tanto ambientales como turísticos están al orden del día, más aún si consideramos la fuerte estacionalidad de los flujos turísticos, muy concentrados en los meses de verano (figura 1).

La importancia de las áreas protegidas de Ecuador como soporte fundamental de su oferta turística se explica por ser uno de los 17 países de mayor biodiversidad del mundo y por ocupar el segundo lugar en número de especies endémicas, además de contar con 17 diferentes ecosistemas y con un 35\% de su extensión territorial cubierta por biomas no perturbados, sobre todo en la región del Amazonas. Su Sistema Nacional de Áreas Protegidas (SNAP) abarca, de hecho, el 13,64\% del territorio nacional, con un total de 64 espacios protegidos y una extensión de 18.401 .927 has. (figura 3). La diversidad biológica es fundamental, en consecuencia, para el desarrollo económico nacional y es un elemento fundamental de sus estrategias nacionales y regionales de desarrollo turístico sostenible, al menos a nivel de discurso teórico, habida cuenta del gran potencial, insuficientemente explorado aún, y de los beneficios derivados de la conservación del medio natural y el mantenimiento de sus señas de identidad eco-culturales e indígenas para convertirse en un destino turístico de primer orden. 


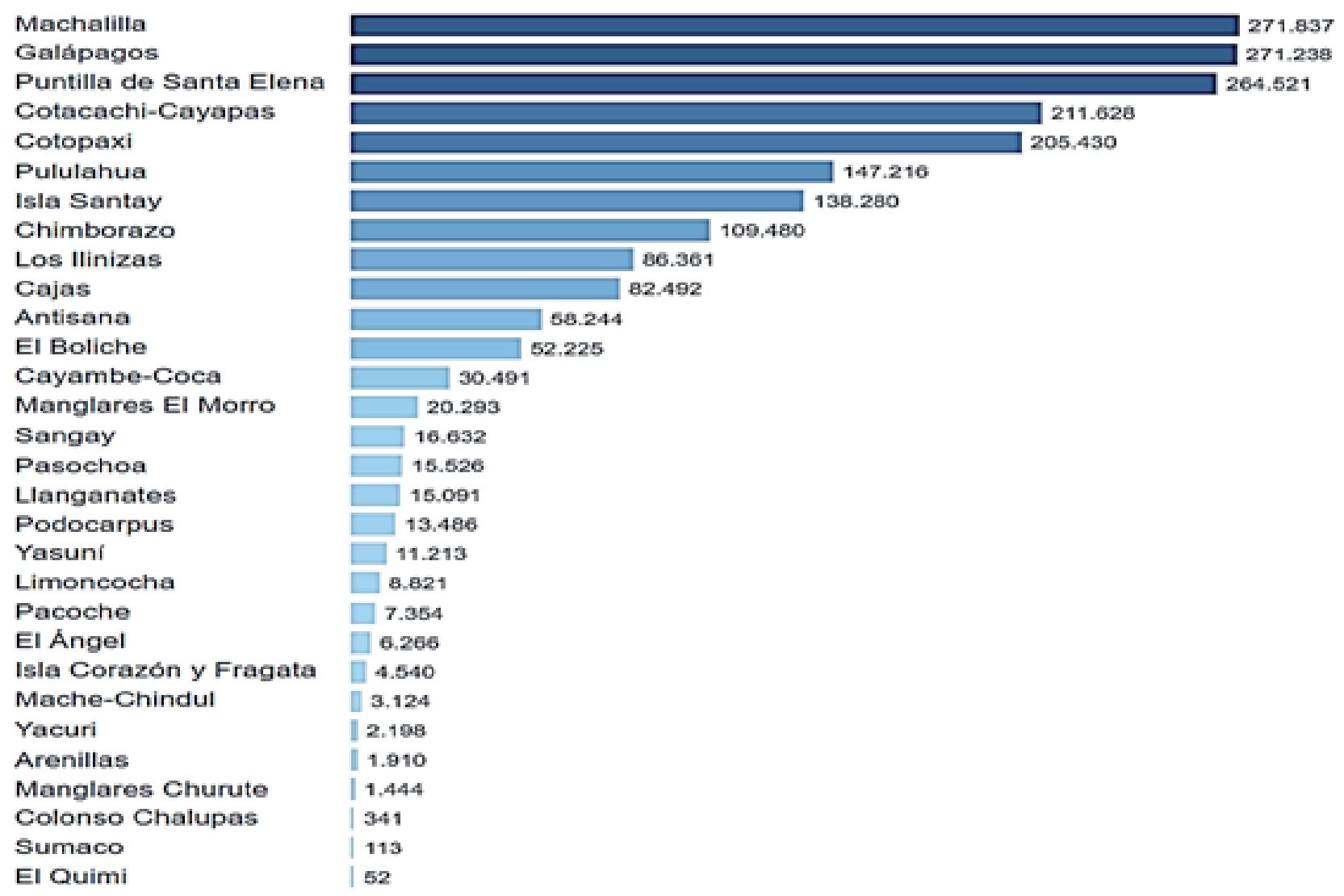

Figura 2. Visitantes en Áreas Protegidas de Ecuador (2019). Fuente: Ministerio del Medio Ambiente (2020). Elaboración propia.

Como ya fue diagnosticado por el Ministerio de Turismo de Ecuador (MINTUR, 2017) este país forma parte del $30 \%$ de los países con un mayor potencial a nivel mundial de desarrollo turístico atendiendo a la calidad y diversidad de sus recursos naturales y culturales. Actualmente, hay registrados unos 3.366 atractivos turísticos a nivel nacional, de los cuales el 3\% se ubican en la región insular de las Galápagos, el 28\% en la región Costa, el 53\% en los Andes y el 17\% en la Amazonia, mientras que el 51\% de dichos atractivos corresponden a manifestaciones culturales y el $49 \%$ a sitios naturales. Para el Ministerio del Ambiente (2020) los espacios naturales que forman parte del Sistema Nacional de Áreas Protegidas (SNAP) vienen experimentando en los últimos años un nivel de afluencia de visitantes aceptable y a buen ritmo gracias a la presencia de los visitantes nacionales, que suponen un $95 \%$ del total, mientras que la demanda internacional es de solo un 5\%. La cifra total de visitantes más actualizada es de 368.309 personas en el conjunto de las áreas de conservación del país (MAE, 2020).

Los turistas que visitan Ecuador realizan principalmente, por este orden, actividades de turismo cultural (un $73,8 \%$ ), ecoturismo (21\%), sol y playa (10,2\%), turismo deportivo de naturaleza y de aventura (3,9\%), turismo de salud $(2,7 \%)$, turismo rural comunitario $(1,3 \%)$ y parques temáticos $(1,3 \%)$, pero en cualquier caso una buena parte de los mismos valora especialmente el nivel de conservación, autenticidad y diferenciación de los recursos naturales y culturales. El Ministerio de Turismo (MINTUR, 2017) señale que las nuevas formas de turismo responsable y sostenible son precisamente las que presentan mayores potencialidades de futuro a medio y largo plazo. Pero para la activación y desarrollo de estas potencialidades, las instituciones gubernamentales y las organizaciones no gubernamentales han de ejercer un papel proactivo y decisivo a la hora de dinamizar turísticamente territorios aún embrionarios en oferta turística y con un tejido empresarial y emprendedor débil y escaso, además de poco vertebrado, y con unas comunidades locales poco sensibilizadas y concienciadas sobre las posibilidades de desarrollo socioeconómico a través de la actividad turística y sus efectos de arrastre en otros sectores de actividad (Idelhadj et al., 2012; Siri \& Sanchai, 2017). Y 
por ello mismo, las políticas públicas han de conseguir que los beneficios e ingresos procedentes de la actividad turística redunden sustantivamente en inversiones y beneficios para dichas comunidades anfitrionas en aspectos diversos como las condiciones de accesibilidad, las infraestructuras y equipamientos públicos, el empleo, la diversificación productiva local, la ordenación sostenible del territorio, etc.

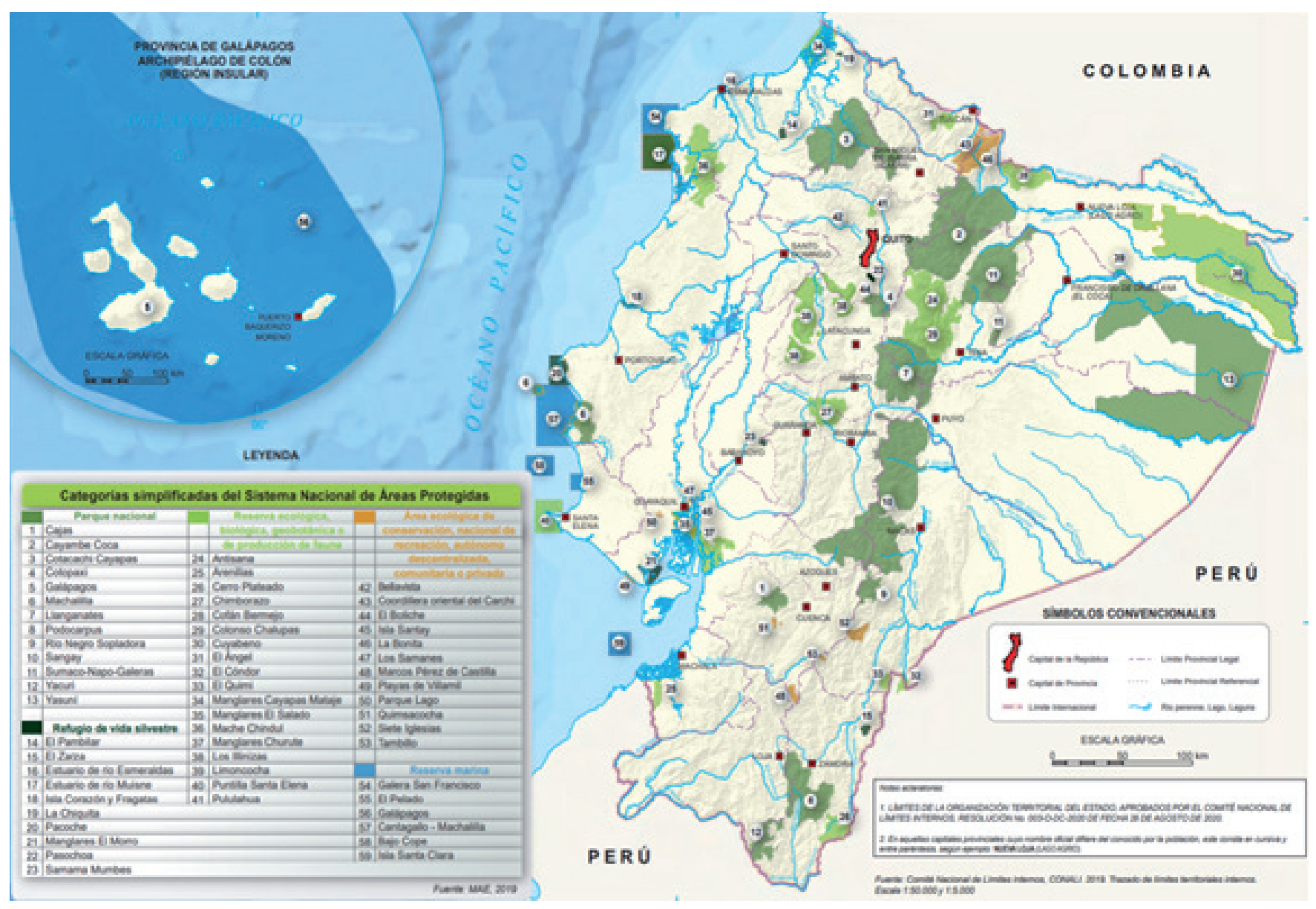

Figura 3. Sistema Nacional de Áreas Protegidas de Ecuador. Fuente: Ministerio del Ambiente de Ecuador, 2019.

En lo que respecta al territorio protegido de Ecuador el Ministerio del Ambiente de Ecuador (2017) especifica que hay sectores muy importantes que aún están fuera de los esquemas de protección y particularmente el $24 \%$ del territorio de vegetación remanente del país corresponde a las zonas necesarias para la conservación de la biodiversidad. De este porcentaje, que equivale a 3,6 millones de hectáreas, el 35\% está dentro del SNAP y el 13\% está incluido en el programa "Socio Bosque" a través de acuerdos de conservación con la comunidad. Un problema que también tiene el país es la exclusión de las zonas planteadas en este estudio para la conservación de las especies.

El artículo 405 de la Constitución de la República de Ecuador 2008 dispone que el Sistema Nacional de Áreas Protegidas (SNAP) garantizará la conservación de la biodiversidad y el mantenimiento de las funciones ecológicas, añadiendo que dicho sistema se integrará por los subsistemas estatal, autónomo descentralizado, comunitario y privado, y su rectoría y regulación estará ejercida por el Estado. Dentro de la normativa derivada se contemplan procesos de protección y cuidado del patrimonio natural de forma participativa mediante distintos subsistemas del SNAP, pero es necesario abordar la realidad de las distintas áreas protegidas de Ecuador y sus diversas variables de presión a las que son sometidas. Hay que reconocer las problemáticas que tienen las entidades encargadas de la gestión, administración y control para validar el cumplimiento de todas sus funciones y competencias considerando que cuentan con presupuestos limitados y 
modelos de desarrollo muy apegados a modelos tradicionales que dificultan la implementación de modelos de desarrollos mixtos (público/privados) que involucren la cooperación y corresponsabilidad de los actores participantes en todo el proceso de la cadena de valor de los destinos y productos turísticos. En efecto, la incapacidad de lograr una interacción satisfactoria entre estas lógicas y modos de gobernanza ha conducido al final a un diseño inconsistente e incoherente (Unkuch \& Rodrigues, 2017).

El Ministerio del Ambiente (2016) reconoce que en las áreas de protección pública, a pesar del respaldo legal, la aplicación de leyes de gestión ambiental es deficiente. El apoyo institucional podría ser fortalecido pero lo cierto es que existe un muy limitado presupuesto, si bien dependiendo de la región, evidenciando un centralismo extremo y una distribución territorial nada equitativa. Esto se refleja en un personal reducido, falta de capacitación, escasa planificación práctica y sustantiva y poco compromiso de las comunidades y gestores locales. Como resultado los propietarios privados y habitantes de las comunidades de las zonas de influencia y amortiguación ambiental dedican la mayor parte de su tiempo a desarrollar actividades no sostenibles.

Las amenazas directas e indirectas que sufren los espacios naturales protegidos en Ecuador han ido incrementándose desde la primera década de este siglo, pese a los distintos convenios mundiales directamente aplicables a las áreas protegidas nacionales que entraron en vigor y la transposición a la legislación ecuatoriana y su insistencia precisamente en la necesidad de una concertación público-privada y una cooperación comunitaria para afrontar los retos de la sostenibilidad ambiental y turística en estos espacios. Hemos de destacar, en este sentido, la Convención relativa a los Humedales de Importancia Internacional (Convenio Ramsar) de 1971, dedicada especialmente a la protección de los Hábitats de las Aves Acuáticas, la Convención sobre la Protección del Patrimonio Mundial Cultural y Natural (1972), la Convención sobre la Conservación de Especies Migratorias de Animales Silvestres (1979), la Convención de las Naciones Unidas sobre el Derecho del Mar (1982), la Convención Marco de las Naciones Unidas sobre el Cambio Climático (1992) y la Convención de las Naciones Unidas de Lucha contra la Desertificación en los países afectados por sequía grave o desertificación (1994); ésta última adaptada, revisada y aplicada en 2003 en Ecuador.

Para la Secretaría Nacional de Planificación y Desarrollo (SENPLADES, 2017), aun cuando Ecuador ha asignado casi un $20 \%$ de su territorio nacional al SNAP, el sector ambiental recibe limitada atención y recursos presupuestarios. El Fondo de Áreas Protegidas (FAP) genera aproximadamente 600.000 USD por año, lo que, en términos relativos, representa $0,0025 \%$ del PIB o 0,77\% del presupuesto de 2008 del MAE. El gobierno no considera, de hecho, una prioridad estratégica la provisión de financiación para la conservación del SNAP, pese a que en el art. 14 de la Ley Orgánica de la Biodiversidad de Ecuador se expresa que el Ministerio de Turismo junto al Ministerio del Ambiente son los competentes de un efectivo manejo y control de las actividades turísticas en áreas naturales a nivel nacional, regional y local, promoviendo actuar en el manejo correcto de los recursos naturales y culturales dentro y fuera de las áreas protegidas.

Algunos estudios realizados en diversas zonas protegidas de Ecuador (Yanez, 2016) coinciden en considerar que en áreas protegidas como la Reserva Ecológica Manglares Churute (REMCh ), elParque Nacional Yasuní (PNY), la Reserva Biológica Limoncocha (RBL), la Reserva Ecológica Cotacachi Cayapas (RECC), la Reserva Ecológica Mache Chindul (REMACH), el Parque Nacional Podocarpus (PNP) o el Parque Nacional Sumaco Napo-Galeras (PNSNG), entre otras, la problemática principal gira en torno a la pérdida de cobertura de vegetación autóctona, la extracción de madera, el desarrollo de actividades Mineras y/o petroleras, y la caza, pesca y recolección de fauna silvestre de manera furtiva. Pero a estos impactos han de sumarse los problemas vinculados a incendios, crecimiento demográfico, conflictos de tenencia de la tierra, desarrollo de ganadería y pastoreo, erosión, vulcanismo, avances de la frontera agrícola, introducción de especies invasivas en los parques nacionales y reservas ecológicas como de producción faunística. Por otro lado, aparecen problemas dentro de los refugios de vida silvestre y las reservas ecológicas vinculados a la contaminación por aguas residuales, residuos sólidos, la producción camaronera y/o la pérdida de cobertura vegetal. Todo ello demuestra las vulnerabilidades que posee el sistema y la necesidad innegable de poder aplicar modelos de planificación y desarrollo más ajustados a sus realidades y dinámicas socioculturales, socioeconómicas, socioambientales y de gobernabilidad, introduciendo propuestas como el turismo alternativo sostenible como estrategias para la conservación del patrimonio, así como la puesta en valor de este. 
Al hablar del manejo sostenible en las áreas protegidas de Ecuador hay que considerar plantear alternativas que vinculen la diversidad económica con la conservación del medio natural. En términos generales, señala Bonilla (2019), el desarrollo del turismo en las áreas protegidas de Ecuador se enmarca, al menos a nivel de discurso y enfoque teóricos, de acuerdo con las directrices del MAE, por lo que el SNAP brinda facilidades y fiscalización para el desarrollo de la actividad turística. De igual forma, el MAE (2017) declara que, según un estudio del perfil del turista realizado en la Reserva Geobotánica Pululahua, el visitante además de hacer uso del espacio público desea obtener servicios complementarios que aumenten su satisfacción, tales como alimentos y bebidas, hospedaje y recreación. Y en este ámbito, es necesario reconocer las limitaciones de gestión, planificación, inversión, ejecución y control en materia de turismo sostenible que posee el patrimonio natural de Ecuador, sobre todo cuando la dinámica entre oferta y territorio representan a estas como principales motivaciones para llevar a cabo una experiencia turística. Por otro lado, se promueve el turismo como un instrumento estratégico para la generación de impactos positivos dentro de las dimensiones y variables estudiadas en la sostenibilidad como el cambio climático y la actual crisis sanitaria.

\section{RESULTADOS. LAS POLÍTICAS AMBIENTALES Y SU ORIENTACIÓN HACIA EL DESARROLLO TURÍSTICO SOSTENIBLE}

Las políticas ambientales de Ecuador entroncan con un antecedente pionero en América como fue la Convención para la Protección de la Flora, de la Fauna y de las Bellezas Escénicas Naturales de los Países de América, que dio lugar a algunas normas y estrategias a partir de 1942 finalmente asumidas por el Estado de Ecuador, que, si bien tardíamente, avanzaron en una visión más comercial de la naturaleza a un enfoque de protección y conservación de la biodiversidad: en particular, la Estrategia Preliminar para la Conservación de Áreas Silvestres y Sobresalientes de Ecuador (1976), la Ley Forestal y de Conservación de Áreas Naturales y Vida Silvestre (1981), aún vigente, la Estrategia para la incorporación del SNAP en los procesos de planificación y ordenamiento territorial y la participación comunitaria en el manejo y la gestión de estas áreas (1989), la plena institucionalización del SNAP en el marco de las políticas estatales ambientales en 1998 (Columba, 2013) y la Ley de Gestión Ambiental de 2004. El objetivo principal de estas fue "proteger y conservar en su medio ambiente natural, ejemplares de todas las especies y géneros de su flora y su fauna indígenas, incluyendo las aves migratorias" y planteó también la declaración y establecimiento de áreas protegidas específicas. Pese a su fecha ya lejana, lo cierto es que esta Convención es la única de amplio alcance en el ámbito de la conservación en el hemisferio occidental y, de hecho, sigue siendo una referencia inexcusable para la legislación nacional de áreas protegidas y, en algunos casos, como una referencia de calado para la toma de decisiones jurídicas que favorezcan la protección de la naturaleza en aquéllas.

La declaración final contiene disposiciones sobre los derechos y responsabilidades de las Partes Contratantes en sentido amplio, que siguen siendo relevantes y algunas de ellas incluyen obligaciones generales y otras más detalladas. Las principales disposiciones que se aplican son las que instan al establecimiento de áreas protegidas, de manera que el artículo II estipula que los Gobiernos Contratantes establecerán parques o reservas nacionales, monumentos naturales o reservas de regiones vírgenes tan pronto como a juicio de las autoridades del país sea necesario, lo permitan las circunstancias y se notifique previamente a la Unión Panamericana la creación de dichas áreas y de los sistemas administrativos adoptados para su gestión y planificación. Esta convención define cuatro categorías de áreas protegidas (Art. I) que siguen teniendo vigencia y sentido en las distintas regiones de Ecuador:

1. Los parques nacionales, establecidos para la protección y conservación de las bellezas escénicas naturales y de la flora y fauna de importancia nacional, así como para su disfrute por parte de la ciudadanía.

2. Las reservas nacionales, establecidas para la conservación y utilización, bajo vigilancia oficial, de las riquezas naturales, en las cuales se dará a la flora y la fauna la máxima protección que sea compatible con los diversos fines para los que son creadas, entre ellos -al menos en teoría- el desarrollo sostenible de las poblaciones aledañas. 
3. Los monumentos naturales, cuyo fin es conservar algún elemento natural específico tales como especies vivas tanto animales como vegetales y de interés biológico, estético o valor histórico o científico. A estos monumentos se les da una protección absoluta y en ellos sólo permiten los usos de carácter investigador y científico debidamente autorizados, así como las inspecciones de control ambiental pertinentes de las autoridades gubernamentales.

4. Las regiones vírgenes, que son administradas por los poderes públicos en aquellos lugares en los que existen condiciones primitivas de muy alto nivel de conservación en materia de flora y fauna, paisaje, culturas y formas de vida tradicionales, etc., con ausencia de caminos y vías de comunicación para el tráfico rodado de motor y sin explotación comercial apreciable.

La utilización de esta gama de categorías de áreas protegidas en función de una serie de objetivos de conservación y manejo sostenible de estos espacios, tiene en Ecuador su plasmación en una gama aún más amplia de áreas protegidas (tabla 2) que van desde una protección integral y absoluta de determinados espacios hasta la compatibilización con la autorización en otras áreas de determinados usos del suelo y actividades económicas y sociales sometidas a determinadas regulaciones, si bien estas pueden ir más allá de los instrumentos jurídicos ambientales, con lo que ello supone de cierto confusionismo y dispersión legal en la práctica, por ejemplo en lo que se refiere a la prevalencia de determinadas normas sectoriales sobre otras que concurren en un mismo espacio.

En la legislación ambiental de Ecuador también se definen objetivos y estrategias generales para la preservación a largo plazo de los servicios ecosistémicos y todos los componentes bióticos y abióticos de estos espacios naturales, como también de los socioculturales de las poblaciones rurales e indígenas que los habitan. Entre estos objetivos se pueden destacar los siguientes: 1) crear y mantener un sistema o red nacional de áreas protegidas integral, adecuado y representativo de las especies y los ecosistemas importantes, terrestres, marinos y de agua dulce; 2) crear y mantener un sistema o red nacional de áreas protegidas para concretar en la realidad toda la variedad de objetivos de conservación de la naturaleza, desde la protección estricta hasta los múltiples usos posibles; 3) crear y manejar áreas protegidas para aprovechar al máximo su relevancia científica, educativa, recreativa, cultural, social, histórica o arqueológica, en consonancia con sus objetivos primarios de conservación y con las metas estratégicas del sistema de áreas protegidas; 4) promover una política nacional de prevención, control y contención de aquellas especies exóticas invasoras que puedan tener un efecto perjudicial sobre la biodiversidad y las áreas protegidas.

Por otro lado, en dicha legislación nacional también se consideran objetivos específicos relacionados con la conservación de la naturaleza, tales como: 1) hacer efectivas las obligaciones internacionales del país incorporándolas al ordenamiento nacional; 2) proteger y restaurar los hábitats y ecosistemas irreemplazables cuyas características únicas no pueden reproducirse mediante la conservación de otras áreas; 3) proteger las especies en peligro de extinción, amenazadas y endémicas, otorgando la máxima prioridad a las especies que están en peligro de extinción, tanto a nivel local como a escala planetaria, y también a sus hábitats; 4) conservar los hábitats necesarios para el mantenimiento de poblaciones viables de especies migratorias; 5) preservar y mantener pequeñas áreas específicas que merecen especial protección debido a su elevada importancia natural y cultural, o por ser poseedoras de otros valores relevantes para las generaciones presentes y futuras; 6) proteger paisajes terrestres y marinos especiales así como sus ecosistemas, con objeto de proporcionar servicios ecológicos esenciales y sustento económico; 7) proteger y preservar grandes áreas naturales intactas y relativamente exentas de fragmentación, así como ecosistemas naturales gravemente amenazados; 8) promover un enfoque eco sistémico de la conservación de la naturaleza, interconectando las áreas protegidas para formar redes ecológicas e integrando dichas áreas protegidas en el paisaje terrestre y marino circundante; 9) utilizar zonas de amortiguamiento y corredores biológicos para facilitar la conectividad ecológica como parte integrante del sistema de áreas protegidas; 10) proporcionar refugios y espacios para ampliar el área de repartición de determinadas especies, a fin de combatir el impacto del cambio climático; 11) concebir y manejar el sistema de áreas protegidas y los espacios que lo conforman de manera que se refuerce la resiliencia de los ecosistemas y las especies ante el cambio climático y otros factores de cambio global, además de brindar la flexibilidad necesaria para posibilitar un manejo adaptativo y responder así al cambio. 
Tabla 2. Categorías de áreas protegidas reconocidas en la legislación ambiental de Ecuador.

\begin{tabular}{|c|c|}
\hline Categoría & Definición en función de los objetivos de manejo \\
\hline $\begin{array}{l}\text { Categoría IA: } \\
\text { Reserva natural } \\
\text { estricta }\end{array}$ & $\begin{array}{l}\text { Áreas estrictamente protegidas, reservadas para proteger la biodiversidad, así } \\
\text { como sus principales rasgos geológicos o geomorfológicos: Las visitas, el uso } \\
\text { y los impactos están estrictamente controlados y limitados para garantizar la } \\
\text { salvaguarda de los valores de conservación. Estas áreas protegidas pueden } \\
\text { servir como áreas de referencia indispensables para la investigación científica y } \\
\text { la gestión pública del espacio natural. }\end{array}$ \\
\hline $\begin{array}{l}\text { Categoría IB: } \\
\text { Área silvestre }\end{array}$ & $\begin{array}{l}\text { Generalmente son áreas no modificadas o ligeramente modificadas de gran } \\
\text { tamaño, que mantienen su carácter e influencia natural, sin asentamientos } \\
\text { humanos significativos ni permanentes, protegidas y manejadas a efectos de } \\
\text { preservar su estado natural. }\end{array}$ \\
\hline $\begin{array}{l}\text { Categoría II: } \\
\text { Parque nacional }\end{array}$ & $\begin{array}{l}\text { Grandes áreas naturales o casi naturales establecidas para proteger procesos } \\
\text { ecológicos a gran escala, junto con el complemento de especies y ecosistemas } \\
\text { característicos del área, que también revisten un interés de tipo espiritual, } \\
\text { científico, educativo, recreativo y de visita, cuando ello resulta ambiental y } \\
\text { culturalmente compatible. }\end{array}$ \\
\hline $\begin{array}{l}\text { Categoría III: } \\
\text { Monumento o } \\
\text { característica } \\
\text { natural }\end{array}$ & $\begin{array}{l}\text { Estas áreas se establecen para proteger un monumento natural en particular, } \\
\text { que puede ser una formación terrestre, una montaña submarina, una caverna } \\
\text { submarina, un rasgo geológico o incluso un elemento biológico, como una } \\
\text { arboleda antigua. Normalmente son áreas protegidas bastante pequeñas y a } \\
\text { menudo tienen gran atractivo para los visitantes. }\end{array}$ \\
\hline $\begin{array}{l}\text { Categoría IV: } \\
\text { Área de gestión } \\
\text { de hábitats o } \\
\text { especies }\end{array}$ & $\begin{array}{l}\text { El objetivo de estas áreas protegidas es la protección de especies o hábitats } \\
\text { específicos y su manejo refleja dicha prioridad. Muchas áreas protegidas de } \\
\text { categoría IV requieren intervenciones activas y periódicas para responder a las } \\
\text { necesidades de determinadas especies o para mantener los hábitats, pero ello } \\
\text { no es obligatorio para la categoría. }\end{array}$ \\
\hline $\begin{array}{l}\text { Categoría V: } \\
\text { Paisaje terrestre/marino protegido }\end{array}$ & $\begin{array}{l}\text { Un área protegida donde la interacción entre los seres humanos y la naturaleza } \\
\text { ha producido a lo largo del tiempo un área de carácter distintivo, con valores } \\
\text { ecológicos, biológicos, culturales y estéticos significativos. En dichas áreas es vital } \\
\text { salvaguardar la integridad de dicha interacción para proteger y mantener el área, } \\
\text { y conservar sus valores naturales y de otro tipo. }\end{array}$ \\
\hline $\begin{array}{l}\text { Categoría VI: Área } \\
\text { protegida con } \\
\text { uso sostenible de } \\
\text { recursos naturales }\end{array}$ & $\begin{array}{l}\text { Estas áreas protegidas conservan ecosistemas y hábitats junto con valores } \\
\text { culturales y sistemas tradicionales de manejo de los recursos naturales } \\
\text { asociados a ellos. Normalmente son extensas, con una mayoría del área en } \\
\text { condiciones naturales y con cierta importancia de las comunidades rurales que } \\
\text { viven dentro del área o en sus zonas de influencia. Una parte incluye el manejo } \\
\text { sostenible de los recursos naturales y se considera que uno de los objetivos } \\
\text { principales del área es el uso no industrial y de bajo nivel de los recursos } \\
\text { naturales, compatible con la conservación de la naturaleza. Se trata del área } \\
\text { protegida más claramente orientada -por no decir la única- hacia la promoción } \\
\text { del desarrollo sostenible y no meramente hacia la conservación de la naturaleza. }\end{array}$ \\
\hline
\end{tabular}

Fuente: Legislación ambiental de Ecuador. Elaboración propia.

La Administración ecuatoriana también cuenta con una cierta diversidad de situaciones posibles a la hora de plantear un sistema de gestión y planificación de las áreas protegidas, tal como se refleja en la tabla 3 siguiente. De acuerdo con la UICN (2012) la planificación es un instrumento metodológico y organizado para la ordenación y la conservación de las áreas protegidas de una manera integral. Y como se explica en el Congreso Mundial de Áreas Protegidas de la UICN (CMAP, 2007) la planificación del sistema de las áreas protegidas engloba aspectos tan diversos como: 1) la consideración de las áreas protegidas como una preocupación prioritaria nacional; 2) la definición de las relaciones entre las diferentes unidades y categorías de áreas protegidas y otras categorías pertinentes (terrestres o marinas, por ejemplo) de consideración más amplia; 3) adoptar una visión estratégica y proactiva en la gestión de estas áreas protegidas; 4) definir 
las funciones de los principales actores implicados en las mismas y sus conexiones y sinergias como paso previo para implementar líneas de apoyo y colaboración público-privada para garantizar la conservación y la sostenibilidad de estos espacios; 5) garantizar la conectividad de los ecosistemas y evitar su fragmentación mediante mejoras de la gestión de su biodiversidad; 6) identificar los impactos actuales y potenciales de las actividades humanas, tanto las que se originan en zonas circundantes como las que se producen en el interior de las áreas protegidas y afectan a las zonas aledañas, ya sean terrestres o marinas.

Tabla 3. Tipos de gobernanza de las áreas protegidas de Ecuador.

Tipo de Gobernanza

\section{Gobierno}

Comunidades Locales e Indígenas

Propietarios Privados
Descripción como integrante del sistema oficial de áreas protegidas

Modelo Clásico: Áreas de propiedad o de control estatal

Nuevo: Conservación voluntaria por parte comunidades locales e indígenas

Nuevo: Conservación voluntaria por parte de propietarios voluntarios (personas físicas o jurídicas)

Algunos elementos nuevos: ONG, comunidades, empresas.

Cogestión

Fuente: Dudley \& Stolton, 2008.

En el caso de Ecuador se establece en los números 5 y 7 del artículo 3 de la Constitución de la República que son "deberes primordiales del Estado promover el desarrollo sustentable y la redistribución equitativa de los recursos y la riqueza, así como proteger el patrimonio natural y cultural del país". Asimismo, en el artículo 15 de la Constitución se establece que el Estado promoverá, en el sector público y privado, "el uso de tecnologías ambientalmente limpias y de energías alternativas, no contaminantes y de bajo impacto", mientras que, a su vez, el artículo 57 (número 8) reconoce expresamente "como derecho de las comunas, comunidades, pueblos y nacionalidades del país el conservar y promover sus prácticas de manejo de la biodiversidad y de su entorno natural, sin perjuicio de que el propio Estado establezca y ejecute programas específicos, con la participación de estas poblaciones, para asegurar la conservación y utilización sustentable de la biodiversidad". El apartado 15 del artículo 66 de la misma Constitución es también importante en la medida en que reconoce y garantiza a las personas el derecho a desarrollar actividades económicas, entre ellas el turismo, en forma individual o colectiva, conforme a los principios de solidaridad, responsabilidad social y ambiental.

Volvemos a identificar también no pocas referencias a nivel teórico a la inclusión de objetivos genéricos sociales y económicos, así como de gobernanza, en la legislación sobre áreas protegidas de Ecuador, en concreto las que a continuación enumeramos: 1) velar por que se dé un uso sostenible a las áreas protegidas, en consonancia con los objetivos primarios de conservación de las mismas; 2) el mantenimiento de los servicios de los ecosistemas y de los recursos naturales, en línea con los objetivos de conservación establecidos, pero también para asegurar medios de subsistencia y promover el desarrollo sostenible de las poblaciones rurales y ayudar a la sociedad a adaptarse al cambio climático; 3) proporcionar a los valores culturales (históricos, arqueológicos, paisajísticos tanto en el ámbito terrestre como en el marino, sagrados y estéticos) una protección acorde con los mismos objetivos de preservación de la naturaleza; 4) promover oportunidades recreativas para los visitantes locales y los procedentes de lugares más lejanos (turismo); 5) garantizar una participación plena de todos los sectores de la sociedad en la creación y el manejo de áreas protegidas; 6) garantizar un reparto equitativo de los beneficios procedentes de los usos autorizados en las áreas protegidas; 7) reconocer distintos modelos de gobernanza de áreas protegidas, incluidas las conservadas de forma voluntaria por comunidades locales, pueblos indígenas y particulares o grupos de personas, siempre y cuando se ajusten a la definición de área protegida y satisfagan los requisitos establecidos en la legislación; 8) promover la cooperación intergubernamental y la cogestión por parte de múltiples organismos y entidades; 9) proteger las especies, los genes y los genomas de interés económico para la obtención de alimento y fibras, para la medicina y para la investigación científica; 10) proteger los valores inmateriales 
que estas áreas protegidas pueden aportar a las comunidades locales y a los individuos a través de la cultura, el conocimiento, la memoria, el significado espiritual, el bienestar social, la salud mental y física y los valores existenciales.

Pasando de una perspectiva global a un análisis más específico de las directrices para la gestión eficiente de las áreas protegidas en la normativa ecuatoriana de carácter ambiental, particularmente la Ley Forestal y de Conservación de Áreas Naturales y Vida Silvestre de 2004, hemos de hacer referencia a su art. 66, que define y caracteriza el patrimonio de las áreas naturales del Estado como aquel constituido por el conjunto de áreas silvestres que se destacan por su valor protector, científico, escénico, educacional, turístico y recreacional, por su flora y fauna, o porque constituyen ecosistemas que contribuyen a mantener el equilibrio del medio ambiente, correspondiendo al Ministerio del Ambiente la determinación y delimitación de las áreas que forman este patrimonio, sin perjuicio de las áreas ya establecidas por leyes especiales. El Capítulo 3 , art. 72, determina también que en las unidades territoriales y patrimoniales que el Ministerio del Ambiente establezca, se controlará el ingreso de público y sus actividades, incluyendo incluso la propia investigación científica, de manera que se otorgan importantes competencias ejecutivas a este Ministerio, que, además, según el artículo 70, puede incluso expropiar tierras y recursos naturales de propiedad privada enclavadas en las áreas protegidas o instrumentar expedientes de reversión de otras propiedades al Estado, según los casos, cuando existan objetivos de conservación de la naturaleza debidamente justificados. Por su parte, el art. 67 menciona que las áreas naturales del patrimonio del Estado se clasifican a efectos de su administración y gestión en las siguientes categorías: a) Parques nacionales; b) Reservas ecológicas; c) Refugios de vida silvestre; d) Reservas biológicas; e) Áreas nacionales de recreación; f) Reservas de producción de fauna; y g) Áreas de caza y pesca. Y es aquí precisamente donde se refiere la posibilidad y necesidad de desarrollar algunas actividades de turismo sostenible dentro de estos espacios declarados como protegidos, mientras que el art. 68 posterior concreta aún más con la previsión de la formulación de planes de ordenación de cada una de dichas áreas. Por último, el art. 69. establece que la planificación, manejo, desarrollo, administración, protección y control del patrimonio de las áreas naturales del Estado, estará a cargo del Ministerio del Ambiente, pero sin prever lamentablemente ningún instrumento de coparticipación y coordinación en dicha gestión con el Ministerio de Turismo para el caso de la ordenación de los usos turístico-recreativos.

En la ley mencionada se hacen sólo menciones muy genéricas a la planificación y ordenación de los espacios protegidos, sin considerar expresamente que el Sistema Nacional de Áreas Protegidas de Ecuador conforma un conjunto territorial no homogéneo y con características físicas, geológicas o ambientales ciertamente diversas según zonas. Por otro lado, los niveles de desarrollo socioeconómico de sus áreas de influencia también son muy diferentes según territorios; por ejemplo, entre las áreas naturales de la sierra ecuatoriana y las zonas litorales. Igualmente, es importante señalar que a no todas las áreas protegidas y declaradas legalmente como tal en el país se les han asignado funciones de estímulo a las estrategias de desarrollo sostenible de actividades como la turística, ya que en Ecuador existen territorios cuya declaración responde exclusivamente a la preservación ambiental de zonas de especial fragilidad, como es el caso de las áreas de Yasuní, Sumaco, Llanganates y Mazán, entre otras, a lo que hemos de añadir la problemática creciente de los conflictos de usos del suelo y control de las tierras que alcanza en ciertos casos una dimensión preocupante que dificulta la implementación de las estrategias de planificación y sostenibilidad. El hecho, por último, de que en los espacios protegidos en los que se pueden, en principio, desarrollar actividades de educación ambiental y turístico-recreativas y de turismo científico no esté participando activamente el Ministerio de Turismo de Ecuador, ni tan siguiera en la planificación y gestión de proyectos turísticos sostenibles, está limitando la capacidad del Estado a la hora de fomentar activamente las iniciativas de las comunidades rurales de las zonas de influencia de estos espacios y para orientarlas debidamente según criterios de sostenibilidad.

La Visión y Estrategia del año 2017 del Ministerio de Turismo de Ecuador tiene como objetivo convertir al país en un referente turístico y un instrumento clave para el desarrollo sustentable, social y económico del país (MINTUR, 2017). Para la consecución de este objetivo tiene establecidas diversas políticas transversales denominadas "de entorno" que persiguen concretamente: 
- Fortalecer y potenciar la industria turística en el marco de los principios de desarrollo sostenible, respetando las riquezas culturales y naturales del país.

- Incentivar la generación y mantenimiento de las cadenas de valor del turismo, promoviendo la inclusión de la microempresa y de los actores de la economía popular y solidaria, así como garantizar la seguridad y la calidad de los destinos.

- Promover la innovación y el conocimiento en los proveedores de servicios turísticos.

- Potenciar los destinos turísticos del país, a través de la inversión en infraestructura, conectividad y promoción.

\section{DISCUSIÓN}

Pese a los principios constitucionales, ciertamente claros y rotundos, que afectan a la conservación y uso sostenible de las áreas protegidas de Ecuador, el análisis de las escasas figuras legales que los han desarrollado y de las acciones -también contadas de carácter aplicado y sustantivo- que han tenido alguna trascendencia, hemos de coincidir con algunos autores como Guambuguete (2016) en que en la práctica se inculcan con frecuencia las determinaciones de este marco constitucional y legal bien por inobservancia manifiesta de las mismas en las actuaciones públicas y privadas o bien simplemente por inacción y falta de aplicación de medidas sustantivas y coherentes, a lo que se suma no pocas veces la indefinición y confusión jurídicas existentes por la falta de una normativa de desarrollo eficaz. Y, por ende, también es manifiesta la falta de confianza de la ciudadanía y los agentes privados con incidencia en las áreas protegidas respecto a la capacidad de acción de las instituciones y de coordinación y cooperación entre las mismas. Esto es particularmente apreciable en el caso de la praxis gubernamental centrada en favorecer a toda costa el aprovechamiento y extracción de los recursos naturales no renovables con criterios cortoplacistas y economicistas y no el uso sostenible de dichos recursos mediante estrategias de planificación y prevención de impactos que, paralelamente, mantengan el control de dichos recursos y los usos del suelo por parte de las comunidades rurales mediante proyectos de desarrollo endógeno y comunitario que mejoren su calidad de vida de manera compatible con la conservación de sus espacios protegidos.

No obstante, en la legislación ambiental ecuatoriana apenas se incluyen principios y objetivos concretos de desarrollo sostenible en general y turístico en particular. Lo cierto es que estos son en la práctica muy limitados y tangenciales. En realidad, sólo la categoría VI de la clasificación de áreas protegidas indicada en el cuadro 1 permite de manera clara usos del suelo y actividades económicas productivas que sean compatibles con la preservación del medio natural, de manera que la legislación sectorial de carácter ambiental no es consecuente, en la práctica, con los principios constitucionales ya mencionados.

El análisis efectuado de las políticas turísticas en Ecuador revela, por su parte, en lo que se refiere a la "seguridad", que este concepto integra en sentido amplio no sólo la seguridad policial y de orden público y la lucha contra la criminalidad, sino también otras vertientes como los sistemas de prevención y atención de accidentes, los servicios sanitarios, la seguridad alimentaria, las buenas prácticas sociales, la seguridad ambiental, etc. En definitiva, se pretende abordar una seguridad de carácter integral de cara al turista, a la vez que cuidando particularmente la propia percepción que pueden tener los visitantes, intermediarios y prestadores de servicios turísticos. Pero este pilar básico no prevé, sin embargo, acciones planificadas de carácter regional o subregional adaptadas a las diferentes realidades y casuísticas de los distintos destinos turísticos ecuatorianos en materia, por ejemplo, de accesibilidad, información turística, sensibilización turística ambiental, etc., por lo que se fijan únicamente una serie de medidas muy generalistas y excesivamente "planas", cuya aplicabilidad y resultados tangibles se están poniendo en entredicho por la inexistencia de planes regionalizados más sustantivos y realistas que, por ejemplo, se adapten a las realidades territoriales más singulares de los espacios naturales protegidos.

En lo que respecta a la promoción de los destinos y productos turísticos el Ministerio de Turismo plantea un pilar básico que busca mejorar la competitividad de Ecuador como destino turístico para su desarrollo económico integral. En particular, se manifiesta el objetivo estratégico de generar destinos turísticos 
sostenibles y competitivos en los que se desarrollen productos turísticos innovadores a través de una adecuada planificación territorial. Pero, de la misma manera que hemos comentado anteriormente, el enfoque adoptado para alcanzar este pilar básico es excesivamente general, ya que se obvia, por ejemplo, la realidad singular de las áreas protegidas, pese a ser éstas las que conforman los principales destinos turísticos ecuatorianos por volumen de visitantes a nivel regional, según el Sistema de Información de la Biodiversidad (MAE, 2016).

La importante concentración de los flujos turísticos en los espacios naturales protegidos a la que nos hemos referido en el apartado 3 de este estudio, exige prioritariamente establecer medidas sustantivas que mejoren la gestión ambiental y turística, además de sus infraestructuras y equipamientos de uso público. Asimismo, la necesidad de planes rectores de ordenación y de uso y gestión de estas áreas protegidas se hace si cabe más necesaria si consideramos el beneficio que pueden generar para comunidades y pueblos ancestrales ubicados en su interior o áreas de influencia socioeconómica. No es una casualidad, en este sentido, que el SNAP (Sistema Nacional de Áreas Protegidas) haya generado unos ingresos anuales que bordearon los 527 millones USD en el año 2014 y que representaron en torno al 35\% de los ingresos totales turísticos del Ecuador. Y, por añadidura, los visitantes extranjeros que visitan la red de espacios protegidos del SNAP gastan en promedio unos 2797 USD de media en sus visitas, aproximadamente 1200 USD más que el turista extranjero que visita otros destinos de Ecuador especializados en otros segmentos de demanda como el sol y playa, el cultural, el rural generalista, etc. (Ministerio de Ambiente, 2020).

El Ministerio del Ambiente de Ecuador (MAE, 2019) afirma que cerca del $70 \%$ de los turistas extranjeros que se acercan a estas áreas protegidas está motivado por la observación y contacto directo con la naturaleza con fines también de conocimiento y aprecio de la misma, pero también gusta de realizar complementariamente algunas actividades dentro de las Áreas Protegidas como la práctica de actividades blandas de carácter físico-deportivo como el senderismo y en menor medida las relacionadas con los deportes de aventura y de mayor riesgo, si bien con el inconveniente de que este tipo de prácticas apenas cuentan con una regulación y ordenación turística y tan sólo están afectadas por alguna regulación ambiental un tanto laxa. Este es un caso más que hace más necesaria la adopción de políticas públicas más orientadas hacia la planificación y gestión estratégica de los recursos territoriales de las áreas protegidas si realmente se pretende convertir estas en un verdadero instrumento de desarrollo turístico sostenible. Pero lo cierto es que, aunque las políticas y programas de turismo en Ecuador se refieren a nivel de discurso teórico a la importancia de desarrollar modelos turísticos sostenibles adaptados a estos espacios protegidos como el turismo rural comunitario, este no es en la práctica una prioridad en la aplicación de programas y experiencias concretas que aborden la problemática integral del turismo de estas áreas protegidas y sus necesidades de desarrollo (Mendoza, 2016).

La Visión estratégica del Ministerio de Turismo referida al pilar básico de la calidad turística en Ecuador tiene, asimismo, que adaptarse a las características territoriales específicas de los espacios naturales protegidos y ha de acompañarse paralelamente de una planificación ambiental y de regulación de usos y sistemas de gestión y gobernanza como también de implantación de estándares de calidad y sostenibilidad ya reconocidos y contrastados en otros territorios similares (Sayda et al., 2020; Ward, Stringer \& Holmes, 2018). Y, en relación con los objetivos se sostenibilidad, la conectividad en materia de transporte público, accesos, multimodalidad de medios no motores, etc. con los mercados nacionales e internacionales, es otra de las prioridades, pero en la práctica las infraestructuras de soporte de la accesibilidad en diferentes regiones del país, sobre todo en las zonas litorales, presentan fuertes deficiencias como resultado, una vez más, de una política excesivamente centralizada en la atención de las necesidades de las grandes ciudades, una escasa capacidad de gestión y aplicabilidad de proyectos de desarrollo integral a nivel local y provincial y fuertes limitaciones para la inversión nacional y extranjera en el sector turístico, lo que ha venido apuntándose ya en algunos estudios recientes (Herrera \& Maria, 2020). En este sentido, pese a que Ecuador ha ascendido en el ranking de desempeño de competitividad turística desde 2009, cuando ocupaba el puesto 96 según el Foro Económico Mundial, en 2019 aún sigue ocupando un puesto bajo en dicho ranking (70/140) y en el último quinquenio ha ido perdiendo competitividad, así como niveles de empleo, llegadas en turismo y otras variables como la sostenibilidad turística y ambiental (Schwab \& Zahidi, 2020). 


\section{CONCLUSIONES}

En este trabajo se han analizado las principales declaraciones y normas internacionales que más han incidido en la articulación e inspiración de las políticas ambientales y en materia de sostenibilidad que afectan a las áreas protegidas de Ecuador y al conjunto del país y que, al mismo tiempo, inciden en las políticas sectoriales de turismo. Estas áreas protegidas conforman los principales destinos turísticos de Ecuador tanto para turistas nacionales como extranjeros, que tienen además un gasto turístico medio superior al de los visitantes de los destinos de sol y playa y otros de carácter cultural y rural. En lo que respecta a la normativa nacional, se ha profundizado particularmente en el análisis de la Ley Forestal, de Biodiversidad y Vida Silvestre, que establece la posibilidad de realizar actividades de desarrollo sostenible dentro y fuera de zonas protegidas siempre y cuando sean compatibles con la conservación del medio natural y la preservación de sus servicios ecosistémicos, si bien las determinaciones de esta normativa son de carácter muy teórico y genérico y no han sido objeto de un necesario desarrollo reglamentario más sustantivo.

En cuanto a las políticas públicas de turismo desafortunadamente no se proyectan en la misma acciones y ordenaciones específicas para el turismo rural y de naturaleza y la sostenibilidad turística de las áreas protegidas, pese a ser estas las que conforman una parte importante de los principales destinos turísticos del país y presentar unos altos índices de biodiversidad y calidad paisajística. Sus planteamientos, en fin, son también excesivamente generalistas y a nivel de discurso teórico, sin existencia de una planificación turística territorializada por regiones, subregiones, tipologías de destinos turísticos y de segmentos de demanda. A la falta de una hoja de ruta bien definida y sustantiva tanto para las políticas ambientales como turísticas en el ámbito de los espacios naturales protegidos de Ecuador, se une la existencia de numerosos puntos de colisión, falta de coherencia y descoordinación entre las políticas ambientales y las de carácter sectorial y territorial como las de turismo y ordenación del territorio, como consecuencia de la falta de una visión estratégica y de planificación territorial integral de los espacios naturales protegidos como destinos turísticos sostenibles y la inexistencia de un marco de gestión, ordenación y planificación compartida y colaborativa entre los distintos organismos que inciden en dichos espacios con sus diversas políticas sectoriales.

La realidad y la problemática que actualmente presenta buena parte de las áreas protegidas en el país, denotan la falta de una política proactiva que promueva la gestión sostenible del turismo en estos espacios, de manera que no sólo se está poniendo en cuestión el desarrollo sostenible, sino que peligra la propia conservación de sus recursos territoriales, ciertamente muy frágiles, frente a un crecimiento espontáneo, desordenado y a veces exponencial de la demanda turístico-recreativa. Los resultados obtenidos del análisis crítico de las normativas y políticas indicadas apuntan a la necesidad perentoria de acciones específicas y adaptadas a la realidad territorial de estos espacios naturales protegidos, pero para ello se requieren cambios profundos en las formas de actuar de la propia Administración Pública a la que compete su gestión, así como una nueva dinámica de gobernanza en la que primen los principios de cooperación, corresponsabilidad y participación.

Por otro lado, el diagnóstico realizado sobre la ordenación y planificación de estas áreas protegidas nos ha revelado, asimismo, la existencia de importantes déficits de información respecto a la mayoría de los aspectos relacionados con el desarrollo turístico de estos territorios, la incidencia de esta actividad en la estructura socioeconómica y empresarial de su área de influencia, los impactos territoriales de carácter ambiental y sociocultural o incluso sobre el mismo perfil de la demanda actual y/o potencial que busca actividades de carácter turístico-recreativo en contacto directo con el medio natural. Y no es menos cierto también que existen carencias importantes de comunicación entre los gestores de estos territorios y el resto de los agentes implicados, especialmente con la propia población local, los emprendedores y hasta los propios visitantes; lo que se agrava, aún más, con la existencia de una oferta turística dispersa y muy desestructurada, que sufre los problemas propios de un desarrollo emergente, espontáneo y desordenado y que no responde a los criterios de calidad que satisfagan realmente las expectativas de los visitantes, al menos de aquéllas que se promocionan a través de los intermediarios y operadores turísticos privados y la propias campañas de marketing de las Administraciones Públicas. 


\section{Declaración responsable y conflicto de intereses}

Los autores declaran que no existe ningún conflicto de interés con relación a la publicación de este artículo. Las tareas se han distribuido entre los autores de la siguiente manera: Los tres autores han participado en la revisión bibliográfica y estado de la cuestión, el diseño de la metodología y la redacción del artículo. La aportación del análisis cuantitativo y actualizado de datos estadísticos de turismo y medio ambiente ha estado a cargo de Manuel Rivera.

\section{REFERENCIAS}

Bonilla Maldonado, D. (2019). El constitucionalismo radical ambiental y la diversidad cultural en América Latina. Los derechos de la naturaleza y el buen vivir en Ecuador y Bolivia. Revista de Derecho del Estado, 42, 3-23. https://doi. org/10.18601/01229893.n42.01

Columba Zárate, K. (2013). Manual para la Gestión Operativa de las Áreas Protegidas de Ecuador. Ministerio del Ambiente.

Comisión Mundial de Áreas Protegidas de la UICN (2007). Establecimiento de redes de áreas protegidas marinas. Guía para el Desarrollo de capacidades nacionales y regionales para la creación de redes AMPs. https://www.iucn.org/sites/dev/ files/import/downloads/mpa_networkes.pdf.

Conap (1999). Política nacional y estrategias para el desarrollo del sistema guatemalteco de áreas protegidas. N.A.P.

Convention on Biological Diversity (CBD) (2010). The Strategic Plan for Biodiversity 2011-2020 and the Aichi Biodiversity Targets. https://www.cbd.int/doc/decisions/cop-10/cop-10-dec-02-en.pdf.

Coreau, A., Guillet, F. \& Rabaud, S. (2018). The influence of ecological knowledge on biodiversity conservation policies: A strategic challenge for knowledge producers. Journal for Nature Conservation, 46, 97-10. https://doi.org/10.1016/j. jnc.2017.10.008

Forleo, M. \& Palmieri, N. (2018). A framework for assessing the relational accessibility of protected areas. Journal of Cleaner Production, 194, 594-606. https://doi.org/10.1016/j.jclepro.2018.05.149

Gibson, F., Rogers, A.S., Roberts, A., Possingham, H., Mccarthy, M. \& Pannell, D. (2017). Factors influencing the use of decision support tools in the development and design of conservation policy. Environmental Science \& Policy, 70, 1-8. https://doi.org/10.1016/j.envsci.2017.01.002.

Guambuguete, J.P. (2016). Análisis del Art. 407 de la Constitución de la República del Ecuador sobre el Principio de Intangibilidad de las Áreas Protegidas. http://www.dspace.uce.edu.ec/bitstream/25000/7908/1/T-UCE-0013-Ab-378.pdf

Herrera C. \& Maria, Jh. (2020). Análisis de las políticas públicas de turismo en Ecuador Periodo 2009-2013. Universidad Andina Simón Bolívar, Sede Ecuador, Área de Estudios Sociales y Globales. T3359-MRI-Herrera-Analisis.pdf (uasb.edu.ec)

Idelhadj, A., Rivera, M. \& Rodríguez, L. (2012). Turismo responsable, espacios rurales y naturales y cooperación para el desarrollo: a propósito de la "Declaración de Tetuán" (Marruecos). Pasos. Revista de Turismo y Patrimonio Cultural, 10(5), 651-664. https://doi.org/10.25145/j.pasos.2012.10.079

Instituto Geográfico Militar de Ecuador (2020). Atlas Turístico del Ecuador: cuatro municipios por descubrir. Ministerio de Turismo. https://servicios.turismo.gob.ec/atlas-turistico

Lausche, B. (2011a). Guidelines for Protected Areas Legislation. IUCN (Unión Internacional para la Conservación de la Naturaleza).

Lausche, B. (2011b). Directrices para la legislación relativa a áreas protegidas. UICN (Unión Internacional para la Conservación de la Naturaleza).

Lundberg, E. (2015). The level of tourism development and resident attitudes: A comparative case study of coastal destinations. Scandinavian Journal of Hospitality and Tourism, 15(3), 266-294. https://doi.org/10.1080/15022250.2015.1 005335

Meinard (2017). What is a legitimate conservation policy. Biological Conservation, 213, 115-123. https://doi.org/10.1016/j. biocon.2017.06.042

Mendoza Ramos, F.M. (2016). Análisis de las políticas para el turismo en Ecuador con énfasis en el turismo rural comunitario. Revista San Gregorio, 15, 122-127.

Ministerio del Ambiente de Ecuador (2016). Áreas protegidas de Ecuador, Socio estratégico para el desarrollo. MAE. 
Ministerio del Ambiente Ecuador, MAE (2017). Lineamientos para la creación y gestión de Áreas de Conservación y Uso Sustentable Autónomas Descentralizadas, Comunitarias y Privadas. Ministerio del Ambiente, 5-70. https://info.undp.org/ docs/pdc/Documents/ECU/Lineamientos\%20creacion\%20areas\%20conservacion2017.pdf

Ministerio de Turismo de Ecuador, MINTUR (2019, 14 de julio). Inventario de Atractivos Turísticos de Ecuador. https://www. turismo.gob.ec/ministerio-de-turismo-actualiza-el-levantamiento-de-atractivos-turisticos-a-nivel-nacional/.

Ministerio de Turismo de Ecuador, MINTUR (2017). Políticas Públicas sobre Turismo en Ecuador. Gobierno de Ecuador.

Ministerio del Ambiente (2016). La gestión integral de las áreas protegidas es una prioridad para el Ministerio del Ambiente. https://www.ambiente.gob.ec/la-gestion-integral-de-las-areas-protegidas-es-una-prioridad-para-el-ministerio-del-ambiente/

Ministerio del Ambiente (2020, 22 de abril). https://www.ambiente.gob.ec/covid-19-un-respiro-para-la-naturaleza/

Mulero, A. \& Rivera, M. (2019). Turismo de naturaleza y espacios naturales protegidos en España. Abaco: Revista de cultura y ciencias sociales, 98, 84-96

Naciones Unidas (2018). La Agenda 2030 y los Objetivos de Desarrollo Sostenible: una oportunidad para América Latina y el Caribe (LC/G. 2681-P/Rev. 3), Santiago.

Ngo, T., Lohmann, G. \& Hales, R. (2018). Collaborative marketing for the sustainable development of community-based tourism enterprises: Voices from the field. Journal of Sustainable Tourism, 26(1), 1-19. https://doi.org/10.1080/0966 9582.2018.1443114.

Organización Mundial de Turismo \& Secretaría de RAMSAR (2019, 14 de junio). Destinos de humedales apoyando el turismo sostenible. https://www.e-unwto.org/doi/pdf/10.18111/9789284414703

Paz Carmona, A.J. (2018). Un tercio de las áreas protegidas en el mundo bajo amenaza humana. MONGABAY LATAM. https:// es.mongabay.com/2018/05/areas-protegidas-amenazadas-por-el-hombre/

Sayda, Marlene, Unkuch, Saant \& Rodrigues, C.M. (2017). Gobernanza e instrumentos de política: un análisis de la política de turismo comunitario del Ecuador. Revista Latinoamericana de Políticas y Acción Pública, 4 (2), 59-83. https://doi. org/10.17141/mundosplurales.2.2017.3073

Schwab, K., Martin, C., Samans, R., Moavenzadeh, J. \& DrzeniekHanouz, M. (2017). The Travel \& Tourism Competitiveness Report 2017. World Economic Forum and R. Crotti \& T. Misrahi (Eds.).

Secretaría del Convenio sobre la Diversidad Biológica (2010). Perspectiva Mundial sobre la Diversidad Biológica. https:// www.cbd.int/doc/publications/gbo/gbo3-final-es.pdf.

Secretaría Nacional de Planificación y Desarrollo, SENPLADES. (2017). Plan Nacional de Desarrollo. Todo una Vida 20172021. http://www.buenvivir.gob.ec/versionesplannacional;jsessionid=DD521DB879E2E0EFA2A620A44FBC8DD

Siri, R. \& Sanchai, O. (2017). Local community participatory learning with a nature interpretation system: A case study in Ban Pong, Chiang Mai, Thailand. Kasetsart Journal of Social Sciences, 38(2), 181-185. https://doi.org/10.1016/j. kjss.2016.04.003

Schwab, K. \& Zahidi, S. (Ed.) (2020). The Global Competitiveness Report, Edition 2020. WEF.

Unión Internacional para la Conservación de la Naturaleza, UICN (2011). Orientaciones futuras de la acción sobre biodiversidad en el ultramar de Europa. https://portals.iucn.org/library/sites/library/files/documents/2011-024-Es.pdf.

Unión Internacional para la Conservación de la Naturaleza, UICN (2013). Conservación Ahora. https://cmsdata.iucn.org/ downloads/revista_web_sur.pdf.

Unión Internacional para la Conservación de la Naturaleza, UICN (2019). Gobernanza de áreas protegidas: de la compresión a la acción. http://cmsdata.iucn.org/downloads/iucn_spanish_governance_book.pdf.

Ward, C., Stringer, L. \& Holmes, G. (2018). Changing governance, changing inequalities: Protected area co-management and access to forest ecosystem services: a Madagascar case study. Ecosystem Services, 30, 137-148. https://doi. org/10.1016/j.ecoser.2018.01.014

Wyborn, C. \& Bixler, R.P. (2013). Collaboration and nested environmental governance: scale dependency, scale framing, and cross-scale interactions in collaborative conservation. Journal of Environmental Management, 123, 58-67. https://doi.org/10.1016/j.jenvman.2013.03.014.

Yánez, M., P., Benavides, J. \& Quishpe, C. (2013). Multivariate characterization of the entities that make up the patrimony of natural areas of the Ecuadorian State: Phase I. La Granja, 18(2), 5-32.

Yánez, M. (2016). Las Áreas Naturales Protegidas del Ecuador: características y problemática general. UNIBE. 